\title{
The Present Moment in Psychotherapy and Everyday Life
}

\author{
Geon Ho Bahn \\ Department of Psychiatry, Kyung Hee University School of Medicine, Seoul, Korea
}

\section{정신치료와 일상생활의 현재 순간}

반 건 호

경희대학교 의학전문대학원 정신건강의학교실

저 자: Daniel N. Stern

출판사: W.W. Norton \& Company, New York

출간연도: 2004 (ISBN: 0-393-70429-7)

Daniel Stern(1934 2012)은 정신과 전문의이며 정신분석 가였다. 사망 직전까지 미국 코넬 의과대학 정신과 겸임교수 및 스위스 제네바대학 심리학과 명예교수를 지낸 저자는 30 년 이상을 발달심리학과 정신역동적 정신치료의 발전에 기 여하였다. 1990년대 초, 저자는 정신분석, 정신치료, 발달심 리학, 소아과 영역의 전문가들과 “보스톤 변화과정 연구회(Boston Change Process Study Group, BCPSG)'를 구성하여 서 로의 이론과 경험을 공유하기 시작하였다. 그 작업 내용은 이 책에 충분히 녹아들었다. BCPSG의 주요 구성원은 Nadia Bruschweiler-Stern, ${ }^{1}$ Alexandra Harrison, ${ }^{2}$ Karlen LyonRuth, ${ }^{3}$ Alexander Morgan, ${ }^{4}$ Jeremy Nahum, ${ }^{5}$ Louis Sander, ${ }^{6}$ Edward Tronick ${ }^{7}$ 이며, 이들은 대부분 보스턴 정신분석협회 소속이다.

저자는 발달심리학 중에서도 유아발달 분야에서 심도 있 는 업적을 남겼다. 특히 유아와 엄마의 상호작용을 분석하기 위하여 동영상을 촬영하고 관찰하는 기법을 도입하였다. 필 름을 분석하는 과정에서 엄마와 아기의 상호작용 중 의미 있

Address for correspondence: Geon Ho Bahn, MD

Department of Psychiatry, Kyung Hee University School of Medicine, 23 Kyungheedae-ro, Dongdaemun-gu, Seoul 02447, Korea

Tel: +82-2-958-8556, Fax: +82-2-957-1997

E-mail: mompeian@khu.ac.kr

This is an Open Access article distributed under the terms of the Creative Commons Attribution Non-Commercial License (http://creativecommons.org/licenses/by-nc/3.0) which permits unrestricted non-commercial use, distribution, and reproduction in any medium, provided the original work is properly cited.
는 '핵심 순간(key moments)'이 있으며, 그 순간들이 이후 정 신치료 과정에서 행동 변화에 영향을 미친다는 것을 알게 되었다. 치료과정뿐 아니라 일상생활에서도 가까운 인물과 의 관계에서 중요한 역할을 한다는 것을 발견하였다. 저자는 이러한 ‘핵심 순간'을 '현재 순간(present moment)'이라고 명 명하였다. '현재 순간'이란 관계의 맥락에서 심리적 과정들이 아주 작은 지각 단위로부터 어떤 의미가 있는 가장 작은 단위 (gestalt)로 모이는 시간을 말한다. 주관적으로는 간섭이 없는 '지금(now)' 경험하는 것들이다. '현재 순간’은 ‘활력징후 정 동(vitality affect) ${ }^{8}$ 으로 구성된 일련의 극적 긴장과 플롯을 최소화한 극단적으로 짧은 내용의 이야기이다. 이는 기본적 으로 관계 경험을 기반으로 형성된다. 일반화, 설명, 해석, 또는 대사 같은 상위 단계 현상 같은 추상적 개념이 이러한 기본적이고 일화적이며 심리적 경험을 형성한다.

'현재 순간'의 특성은 다음과 같다.

1. 인지(awareness) 또는 의식(consciousness)은 현재 순간 을 위한 필수 상황이다. 이들이 같은 것은 아니지만 '현재 순

${ }^{1}$ Daniel Stern의 아내이며, 소아정신과의사. 스위스 제네바 Brazelton Center의 설립자

${ }^{2}$ 소아정신과전문의, 보스턴 정신분석협회의 교육지도분석가, Harvard Medical School 정신과 외래교수

${ }^{3}$ Harvard Medical School 심리학과 교수

${ }^{4}$ Boston Newton Center 소속 정신과의사

5 정신과전문의이며 보스턴 정신분석협회에 유아연구워크솝을 개설함 ${ }^{6}$ 보스턴 의과대학 정신과 석좌교수, 2012년 타계하였음

${ }^{7}$ University of Massachusetts 아동발달분과의 책임자. 2 4개월 유아 심리연구

${ }^{8}$ Daniel Stern이 처음 사용한 개념으로, 호흡, 맥박, 심박동 등의 활 력징후처럼 살아가는 데 필수적인 정서가 엄마와 아기의 관계에서 필요하다는 의미로 사용 
간'은 의식 중에 발생하는 경험이다.

2. '현재 순간'이 경험의 언어적 영역은 아니지만, 나중에 말로 설명할 수 있다.

3. '현재 순간'의 느낌은 '지금' 인지한 것이다. 그럼에도 불 구하고 '현재 순간'은 알아차리기가 쉽지 않다. 왜냐하면 '현 재 순간'은 주관적 경험이지만, 이는 곧바로 객관적 또는 제 3자의 시각으로 이동하기 때문이다.

4. '현재 순간'은 매우 짧다. 대개 1 10초 범위이며, 평균적 으로는 3 4초 정도이다. 이 시간이 중요한 이유는 첫째, 지각 된 자극들이 의미 있는 자극으로 분류되는 데 필요한 시간, 둘째, 행동 수행에 필요한 기능적 단위를 구성하는 데 필요 한 시간, 셋째, 의식 수준으로 올라오도록 승인하는 데 걸리 는 시간이기 때문이다.

5. '현재 순간'은 심리적 기능이 있다. 예를 들어, 누군가 당 신에게 “달에 대해 생각합시다"라고 하면 달에 대한 이미지 가 마음속에 떠오른다. 목적, 또는 의도를 갖게 된다. 이처럼 '현재 순간'은 심리적 작업을 수행한다.

6. '현재 순간'은 전체론 또는 게슈탈트이다. 의식 아래에 있던 작은 지각 단위(음소문자나 노트)를 상위 단위로 끌어 올려 의미 있는 구절로 조직하는 것이다. 좋아하지 않는 이에 게 “안녕”이라고 인사하는 것을 가정하자. 그렇게 하기 위해 서는 제 3 자 입장이라면 자신의 감정, 인지, 감각, 지각, 행동 을 각각 분리할 수 있을 것이다. 하지만 일인칭 모드에서는 이를 분리할 수 없고, 전체로 느껴야 한다.

7. '현재 순간'은 일시적이나마 역동적이다. 심리적 현상에 대한 사고 내용은 실제 경험에 대한 일시적 시간 역동에 무 심한 편이다. 반면, '현재 순간'은 상당히 시간 역동적이며, 이 러한 역동적 시간 형태를 활력징후 정동이라고 칭한다. 활력 징후 정동은 아기를 향한 엄마의 정서적 조율을 설명하기 위 해 도입된 개념이다. 상호주관성의 초기 형태이기도 하다. 이 러한 활력징후 정동의 ‘일시적 형태'는 음악, 춤 등에서도 나 타난다. Cartier-Bresson이 말한 '결정적 순간(decisive moment)'에서도 볼 수 있다. 사진을 통해 정지된 영상을 보고 있지만, 일시적 형태와 관련된 내용을 상상할 수 있다. 이는 작은 정서적 대사가 된다. 즉, '모래 한 알에 담긴 세상(a world in a grain of sand)'을 보는 것이다.

8. '현재 순간'은 차례로 펼쳐지면서 전개되기 때문에 부분 적으로는 예측 불가능이다. '현재 순간'은 각각 독특하고, 시 간, 공간, 과거 경험, 시시각각 변하는 특이성에 의해 결정되 므로 예측하는 것이 불가하다.

9. 일부 '자기(self)'를 포함한다.

10. '경험 자기(experiencing self)'는 '현재 순간'과 상대적 '자리(stance)'를 잡는다. '자리'란 경험과의 거리, 관련성 여
부, 참여도, 흥미, 정서적 투자, 일어난 일에 대한 평가 등을 말한다. 주관적 자기와 경험 자기, 모두 신경과학적 의미를 밝혀내야 한다.

11. 각기 다른 '현재 순간'은 각각 다른 중요한 의미가 있다. 맥락에 따라 다양한 이름으로 불린다. '시간 속 순간(a moment in time)', '시간 밖 순간(a moment out of life)', '결정 적 순간(the decisive moment, 예: 사진촬영 순간)', '의미부 여의 순간(a defining moment)', '진심의 순간(a moment of truth, 예: 투우 장면)', '이상하고 형편없는 순간(a weird fucking moment, 예: 순간의 결정에 따라 생사가 달린 경찰 전 문 은어)' 등이 있다.

일상생활에서 만날 수 있는 '현재 순간'의 예를 들어보자. '현재 순간'은 상황이 달라지면서 계속 다른 형태로 이어진 다. 어느 날 라디오에서 나오는 국무총리 인터뷰를 들으면서 냉장고에서 버터를 찾았는데 버터가 없다. (이때부터는 인터 뷰가 들리지 않는다) 순간 당황스럽기도 하고 부정적인 감 정도 들고, 실망감과 분노까지 느끼며 점차 심해진다. 이 순 간은 약 3초 정도 지속된다(현재 순간 1). 잠시 후 스스로 말 한다. "괜찮아, 다이어트도 하고 잘됐네." 그러자 분노가 사 라지고 안도감이 든다(현재 순간 2). 이 역시 3초 정도 지속된 다. 그때 냉장고에 꿀이 보인다. "버터 대신 꿀을 발라 먹을 까? 하지만 꿀은 주말에만 먹기로 했었는데.” 그러자 죄책감 과 배신감이 든다(현재 순간 3). 하지만 결국 꿀을 꺼내서 빵 에 바르면서 “내가 지금 빵으로 무슨 짓을 하는 거지?”라는 생각과 함께 부정적 감정이 올라온다(현재 순간 4). 그러면서 도 꿀 바른 빵을 한 입 베어 물고 나자 “흠, 나쁘지 않은데." 하며 기분도 차츰 좋아진다(현재 순간 5). 그러자 다시 국무 총리 인터뷰가 귀에 들어온다. '현재 순간 5' 역시 3 4초 동 안 일어난 일이다.

정신치료 시간에 일어나는 '현재 순간'의 예를 보자. 평소 한 남성 환자와 치료 시작 전, 그리고 끝나고 돌아갈 때 악수 를 하곤 했다. 어느 날 환자는 처음으로 심각한 내용을 이야 기하였다. 치료 시간 내내 이야기 내용에 압도되면서 힘들어 했다. 시간이 끝나고 돌아갈 때 평소처럼 악수하면서 치료자 가 자신의 왼손을 환자의 오른손 위로 얹었다. 말없이 서로 를 바라보았다(현재 순간). 이후 치료가 활발히 진행되었다. 수년 후 치료를 종결할 즈음에 "당신을 변화시킨 가장 중요 한 또는 가장 핵심적인 순간은 언제입니까?”라고 물을 때, 이 환자는 "언젠가 치료가 끝나고 돌아갈 때 나눴던 악수입 니다.”라고 하였다. 악수하고 바라보았던 시간은 불과 몇 초 에 지나지 않았지만, 그 효과는 엄청난 것이었다.

저자가 처음 '현재 순간'에 관심을 갖게 된 아기와 엄마의 상호작용에서 엄마와 아기의 비언어적 '현재 순간'의 길이는 
얼마나 될까? 1) 엄마와 말이 트이지 않은 아기의 음성 교환 은 2 3초 간격, 2) 엄마가 아기에게 불러주는 노랫말도 2 3 초 길이, 3) 아기와 엄마가 마주 보고 놀 때 엄마의 표정, 엄마 의 움직임 등은 순간순간 아기에게 자극을 주고 활성화하는 데 기여하는데 이런 동작들은 2 5초간 지속, 4) 엄마, 아빠, 아기, 삼자 간 활동 간격은 평균 3.5초(2 10초 범위), 5) 아기 는 빠르게 학습이 가능하지만 '현재 순간'의 기간이 중요하 다. 예를 들어, 생후 3개월 된 아기는 '사회적 미소(social smile)'와 '소리내기(vocalization)'를 할 수 있으나, 그에 대 해 부모가 '강화제(reinforcer)'인 미소로 화답하거나 함께 ‘소 리 내주기'는 아기 행동 후 3초 이내에 반응하지 않으면 학 습이 일어나지 않는다. 즉, 아기의 행동과 그에 대한 강화제 가 같은 '현재 순간'에 일어날 때, 아기는 그 두 가지를 연관 지을 수 있다.

저자가 책 제목으로 생각했던 것들을 복기하다 보면 ‘현재 순간의 개념은 물론 책 내용을 이해하는 데 도움이 될 것이 다. 저자가 처음 생각한 것은 '현재 순간'의 미세한 특성을 고 려하여 '모래 한 알에 담긴 세상(a world in a grain of sand)' 이었다. 이 문구는 William Blake의 시에서 인용한 것이다. 두 번째는 '달의 불분명한 쪽(the obscure side of the moon)'이 었다. 미세 세계의 경험을 인지해도 아주 가끔만 의식으로 연결되므로, 대개 외적으로 드러나기보다는 내적인 경우가 많음을 강조하기 위해서다. 따라서 내현화 특성을 고려한 제 목이었다. 셋째, '현재 순간'은 일시적이며, '현재'의 현상학 적 경험이라는 점을 고려하여 '정신치료 경험의 현상학적 시 각(a phenomenological view of psychotherapeutic experience)'을 생각하였다. 넷째, 뭔가가 실제로 바뀌는 것을 의미 하는 그리스어인 'kairos'를 떠올렸다. 과거에 일어난 일을 통해 현재 변화가 일어난다는 점을 고려하면 잘 들어맞는 듯하다. 하지만 kairos가 제목으로 부적절한 이유는 이 단어 가 주로 '한 사람 심리학(one-person psychology)'의 구조를 가리키는 단어로 사용되기 때문이다. 저자가 속한 BCPSG 에서는 '두 사람 심리학(two-person psychology)'을 따른다. 다섯 번째, '만남의 순간(the moment of meeting)'이다. 상호 주관성(intersubjectivity)은 물론 치료 시 변화를 일으키는 주요 인자로 작용하는 상호창조성과 상호주관성 영역이 확 장되는 것을 의미하기도 한다. '두 사람 심리학'의 구성 요소 인 상호주관성에 대한 반영을 통해 새로운 형태의 의식, 즉 '상호주관적 의식'에 도달할 수 있게 된다. 그러나 '만남의 순 간'은 단지 특별한 형태의 '현재 순간'만을 나타내는 듯하여 제목으로 사용하지 않기로 하였다. 여섯 번째 제목 후보는 '정신치료와 일상적 삶의 현재 순간(the present moment in psychotherapy and everyday life)'이었다. 이 제목은 앞서
논의한 여러 가지 의미를 모두 포함하고 있으므로 제목으로 최종 선택하였다.

최근까지 학문적 심리학 분야에서는 '현재 순간' 같은 주 관적 경험 구조와 성질에 대해 관심을 가질 필요를 느끼지 못 했으며, 상대적으로 무시해 왔다. 신경과학의 발전으로 '현재 순간' 같은 주관적 경험에 대한 관심이 늘고 있다. 그렇다면 주관적 경험을 탐색하는 일상적 정신분석 과정과 '현재 순간' 은 무엇이 다른가? 첫째, '현재 순간'은 그 자체로 '모래 한 알 안에 담긴 세상'이다. 분석에서는 그 의미를 깊이 탐색하고 자유 연상을 통해 더 뭔가를 알아내고 해석하려고 시도한다. 그러나 ‘현재 순간'에 머무르고 탐색하는 시간이 길어질수 록, 다른 길로 들어설 가능성이 많아진다. 두 번째 차이는 현 재 경험, 즉, '현재 순간'과 이후 언어적 재건 사이의 관계에 있다. 정신분석은 무엇이 발생했는가보다 재건에 더 관심을 둔다. 경험의 언어적 재구성 측면에 중점을 두다 보면 현상 그 자체를 놓칠 수 있다. 지적 및 언어적 기능은 항상 어떤 일 이 일어났었는지 또는 무슨 일이 일어날지를 토대로 작동하 며, 무엇이 일어나고 있는지를 기반으로 작동되지 않는다.

책의 내용은 변화로 이어질 수 있는 경험의 경과 단위로 '현재 순간'을 소개하고 있다. 1 부는 '현재 순간'을 탐색하며, 1장부터 4장까지 이어진다. 1장 '지금', 2장 '현재 순간'의 특 성 해부, 3장 '현재 순간'의 일시적 구조 검토, 4장 '현재 순 간'의 조직화로 구성된다. 2 부에서는 '현재 순간'이 치료과정 에서 활용될 수 있는 세 가지 성분, 즉 상호주관성, 내재적 지 식(implicit knowledge), 의식(consciousness)을 소개한다. 둘 또는 그 이상의 마음이 서로 꿰뚫고 같은 경험을 대강이나 마 공유할 수 있다. 특별히 환자와 치료자 사이의 상호주관성 이 중요하고, 두 마음이 만나는 순간들이 가장 흥미로운 ‘현 재 만남'이 된다. 5장에서는 치료 장면과 일상적 사회생활에 서의 전반적 상호주관성을 기술한다. 6 장은 정신치료는 물 론 진화를 위한 상호주관성의 적응적 중요성을 다룬다. '현 재 순간'과 관련된 주된 영역은 내재적 지식으로, 7장의 주제 이다. 8장은 의식 차원에서의 '현재 순간’의 입장을 기술한다. 3 부는 임상적 시각에서 '현재 순간'을 다룬다. 9장에서는 임 상 실제에서의 '현재 순간'을 소개한다. 10장은 치료 시간에 순간순간 발생하는 치료과정의 예측 불가능(unpredictability) 과 깔끔하지 않음(sloppiness)'을 논한다. 결과적으로 '지금 순간(now moment)'과 '만남의 순간(moment of meeting)'이 라는 두 가지 특성을 만나게 된다. 이 둘은 마치 볼트와 너트

9깔끔하지 않음'은 부정적 의미가 아니라 완벽하지 않아서 개선의 여지가 많다는 긍정적 의미임. 즉, '시도-실패-재시도-정교하게 마 무리' 과정이 일어나려면 처음부터 말끔하게 처리되는 것이 아니고 대충 처리하거나 또는 헛점이 보이는 것이 좋겠다는 뜻 
같은 존재이다. 11 장은 내재적인 것(implicit)과 외재적인 것 (explicit)의 엮임을 다룬다. 12장에서는 과거와 현재의 순간 을 다룬다. 현재가 어떻게 과거에 의해 영향을 받는지, 현재 는 물론 과거를 붙들고 있어야 하는 필요성은 무엇인지 알 아야 한다. 정신역동적으로 생각할 수 있도록 하기 위해 필
수적이다. 13장은 정신치료적 변화를 일으키기 위한 '현재 순 간'의 역할과 임상적 적용을 제시한다. 부록으로 '미세분석적 면담(micro-analytic interview)' 연구 결과를 요약하여 제시 한다. 